\title{
Effective strategies for nurses empowering the life quality and antipsychotic adherence of patients with schizophrenia
}

\author{
Saida I. El-Azzab*, Entisar M. Abu-Salem \\ Department of Psychiatric/Mental Health Nursing, Faculty of Nursing, Beni-Suef University, Beni-Suef, Egypt
}

Received: December 8, 2017

DOI: $10.5430 /$ jnep.v8n10p106

\author{
Accepted: May 1, 2018 \\ Online Published: May 28, 2018 \\ URL: https://doi.org/10.5430/jnep.v8n10p106
}

\begin{abstract}
Background and objective: Schizophrenia requires preservation of treatment with psychotropic medication and psychoeducational therapy. The nurse uses effective strategies to train those patients about stress management; relaxation technique and increase self-awareness, to improve their quality of life and enhance antipsychotic adherence. The study aimed to assess the effective strategies for nurses empowering the life quality and antipsychotic adherence of patients with schizophrenia.

Methods: Quasi-experimental research design was utilized in this study. The present study was achieved at the outpatient departments of the Mental Hospital in Beni-Suef, Egypt. A non-probability sampling of 60 patients with schizophrenia were recruited for the study. Tools of this study included: A structured interview questionnaire related to soci-demographic data, the quality of life scale, and the medication adherence rating scale. The training program consisted of 8 sessions.

Results: The study indicated that there were statistically significant improvements in the life quality and antipsychotic adherence for patients with schizophrenia after application of psychiatric nursing instructions.

Conclusions and recommendations: The results of this study concluded that psychiatric nursing approaches were effective in the improvement the quality life and adherence to antipsychotic of patients with schizophrenic disorders. Recommendations: This study recommended that a psychiatric nurse must use the effective strategies for empowering the life quality and antipsychotic adherence of patients with schizophrenia.
\end{abstract}

Key Words: Strategies, Adherence, Antipsychotics, Quality of life, Schizophrenia

\section{INTRODUCTION}

Schizophrenia is a mental disorder that normally seems in late puberty or early adulthood. Characterized by hallucinations, delusions, and other intellectual dysfunction, schizophrenia can often be a lifelong struggle. ${ }^{[1]}$ Schizophrenia occurs severe difficulties for patients and their families. In the past, the control of patients' symptoms was the main objective of management for patients with schizophrenia. However, lately improving patient's life quality is now con- sidered an increasingly important objective of treatment. ${ }^{[2]}$ Patients with schizophrenia have a significant insufficiency of psychosocial interactions and the life quality with greater health costs and impact on their emotional state, personality type, adaptation, and treatment consequence. ${ }^{[3]}$

Adherence to pharmacological therapy is essential to relieve psychotic symptoms in schizophrenia. The antipsychotic drugs are effective in approximately $70 \%-80 \%$ of the psychiatric patients; however, an estimated half of the individuals

*Correspondence: Saida I. El-Azzab; Email: saida_hassan@yahoo.com; Address: Department of Psychiatric/Mental Health Nursing, Faculty of Nursing, Beni-Suef University, Beni-Suef, Egypt. 
who react greatly to medications are noncompliant with their medication regimen. ${ }^{[4]}$ According to the World Health Organization, accepted the definition of "therapeutic adherence" is "the extent to which a person's behavior is consistent with agreed recommendations from the health care provider". [5] Antipsychotic drug adherence is basic to improve outcomes in most patients with schizophrenia. ${ }^{[6]}$ The patient requires continuous treatment with the drug in combination with psychosocial therapy. ${ }^{[7]}$

\subsection{Significance of the study}

The adherence to psychotropic drugs that treat a patient with schizophrenia is essential to accomplish recovery objectives and optimize overall wellness, for this patient and family members demand more data about the disease, methods of drug administration, mechanism of action, potential adverse events; and side effects. The nurse has a critical role in improving medication adherence for the patient with schizophrenia. ${ }^{[8]}$ The consequences of non-compliance can be overwhelming, for patients and their' families in terms of personal suffering, hospitalization, reduced the life quality, as well as for society in general due to loss of returns and direct costs of health care. ${ }^{[9]}$

Critical components of the treatment plan for clients with schizophrenia are giving them instructions about general and psychiatric health, psychosocial interaction skills and adherence of drug training which can encourage them to make right decisions about their management. Consequently, nurses can play a vital role in improving medication adherence by collaborating with patients to identify obstacles and working with clients, family members, and other health care providers to recognize effective strategies to enhance medication adherence. ${ }^{[10]}$ When discussing the treatment alternatives, it is beneficial to understand the clients' management objectives, help them to select a drug that meets their personal preferences, and to explain clearly potential treatment-related adverse events. In addition to positive attitudes toward drugs, and the expectation that drugs are effective in decreasing symptoms that contribute to adherence. ${ }^{[11]}$ The patients with schizophrenia disorder demand more professional attention "as a general and especially from the nurse", for their behaviors, drugs administration methods, and how they deal with symptoms, stress management; relaxation techniques, increase contact with reality, improve their quality of life and enhance antipsychotic adherence. Consequently, the current study was carried out.

\subsection{Study aim}

This study aimed to assess the effective strategies for nurses empowering the life quality and antipsychotic adherence of

Published by Sciedu Press patients with schizophrenia.

\subsection{Research hypothesis}

It is supposed that the effective strategies for nurses will be positive in empowering the quality of life and antipsychotic adherence of patients with schizophrenia.

\section{SUBJECTS AND METHODS}

\subsection{Design}

A quasi-experimental design (one group pre-test, post-test and follow up) was adopted to carry this study.

\subsection{Setting}

The study was done in the Outpatient Units of the Mental Hospital in Beni-Suef, Egypt, which is a general mental hospital in Beni-Suef Governorate. Affiliated to the Ministry of Health it provides care to 150 patients both females and males and it provides also inpatient services and all psychiatric services.

\subsection{Subjects}

A sample (purposive sampling) including patients with schizophrenia who were recorded on the follow-up sheets of the outpatient units in the chosen setting and fulfilling the inclusion standards were involved. The subjects were 60 patients.

\subsection{The inclusion and exclusion standards \\ 2.4.1 Inclusion standards}

Patients were included in the study as, the patient with schizophrenia, both genders, 20 old age or older, have insight into his/her disorder and how to manage it. Approving to the Medical Dictionary for the Health Professions and Nursing ${ }^{[12]}$ which demonstrated that the patient's insight means understanding and awareness of the origins and importance of his/her attitudes, feelings, behavior, distressing symptoms, and self-understanding.

\subsubsection{Exclusion standards}

Patients were excluded from this study as, a patient with organic brain syndrome. The patient who has an additional psychiatric disorder. A patient diagnosed with a deficiency in brain function or mental diminishing and received electroconvulsive therapy "ECT". The client that does not have insight into his/her disorder and not know how to manage it. A patient who has recent substance abuse.

\subsection{Tools}

Three instruments were utilized for data collection: A socio-demographic data sheet, the Quality of Life Interview Scale (QOLI), and the Medication Adherence Rating Scale (MARS). 
The tool I: Sociodemographic Data Sheet. It was projected by the researchers and included the patient's age, gender, the degree of education, occupation, married condition, income, number of hospital admissions, duration of illness; present complaints, and current treatment.

The tool II: Quality of Life Interview Scale (QOLI). The original scale was created by Lehman. ${ }^{[13]}$ It was adopted by the researchers to evaluate the life quality of patients with chronic psychiatric disorders. It consisted of 60 items divided into 4 subscales: First subscale, comprising 13 items covering the general level of activity. The second subscale consisted of 19 items reflecting the self-care which was divided into 4 groupings of items; 4 items covering personal hygiene, 5 items representing grooming, 5 items related to patient's nutrition, and 5 items indicating patient's elimination. The third subscale included 15 items, representing the patient's emotional status. The fourth one consisted of 13 items related to the personal and social relationships.

Scoring system: The responses were determined on a 5-point Likert scale, the better the quality of life for all items except the reversed items $(6,8,16,19,28,29,48,5556,57)$, in which the lower the scores the better the quality of life. Reliability of the tool was done: Test-retest reliability of the quality of life interview scale revealed a correlation coefficient of 0.7221 using Pearson's $(r)$ test indicating good reliability

The tool III: The Medication Adherence Rating Scale (MARS). The scale was developed by Thompson, Kulkarni and Sergejew. ${ }^{[14]}$ Adopted by the researchers to determine compliance with antipsychotic drug in patients with psychiatric disorders. It was planned to measure both the patient's attitudes towards medication and also existing drugs-taking behavior. It contains about ten items; (1-4 items) represent compliance with drug behavior, (5-8 items) represent an attitude toward taking medication and (9-10 items) represent negative attitudes and side-effects of psychotropic drugs.

Scoring system: A patient was asked to respond either by 'YES' or 'NO' to each item. A response congruent with nonadherence is coded as zero, whereas a response congruent with adherence is coded as 1. For items 1-6 and 9-10 a "NO" response is a clue to adherence and therefore should be coded as 1; on the other hand, for items 7-8 a "YES" response is a clue to adherence and should be coded as 1 . The total scores range from zero to ten, where the highest score indicated the highest level of positive attitudes and behavior towards antipsychotic adherence. Reliability of the tool was done: Test-retest reliability of the medication adherence rating scale showed a correlation coefficient of 0.8222 using Pearson's $(r)$ test indicating good reliability.

\subsection{Validity}

The validity of the tools were performed before starting the data gathering. The tools were translated into Arabic and verified for their content. It was done by five experts in psychiatric nursing and medical professional, to establish the relevance and comprehensiveness of the items and the necessary modifications were carried out consequently.

\subsection{Pilot study}

A pilot study was accomplished in 6 patients from the Outpatient Units of the Psychiatric Hospital in Beni-Suef Hospital, representing $10 \%$ of the total sample. It was held out to assure the clarity of questions, the applicability of the tools and to estimate the time needed to complete them. The necessary modifications were created based on the outcome of a pilot study. The pilot survey was not included in the main study sample in order not to contaminate it.

\subsection{Ethical considerations}

An oral approval for each participant who agreed to share in the study was taken. The researchers explained the objective of the study to the participants. They sustained on confidentiality and anonymity of subjects' give data that will be utilized for research purpose only. Subjects were also educated that contribution is voluntary, and they had the right to draw from the study at any time without giving any reason.

\subsection{Procedure for data collection}

Before carrying out the study, the researchers got approval from the Committee for Research in the Faculty of Nursing. Then an official approval was obtained from the hospital manager upon a letter issued from the Faculty of Nursing. Reviewing literature related to schizophrenia, pharmacotherapy, stress management, relaxation technique, and increase self-awareness were carried out. Once permission was taken from the director of the hospital to conduct the proposed study, researchers contacted the subjects individually. A structured interview was done for each patient during the period of waiting for the doctor. The questionnaires were read, explained and the choices were recorded by the researchers to the patients who were not able to read and write. The tools used in the study were directed by the researchers, and filling in the questionnaire sheets took about 30-40 minutes.

This study was completed over a 9-month period from the beginning of January to end of September 2017. Data were collected in 2 days per week (Sundays \& Tuesdays). The researchers conducted the interviews during the morning shift (from 9.00 Am to 2.00 Pm). Every 5 patients were categorized as a group (each group interviewed twice per 
week). A procedure of gathering data was guided by phases of Lippitt's theory of modification.

\subsection{Theoretical framework}

Modification theory by Lippitt's recognized the theoretical foundation for the present study. Lippitt supposed that the modification is involved of six phases: Detect the problem, evaluate individual's enthusiasm and capability for change, evaluate modification agents' enthusiasm and resources, select the objective that is progressive, select the applicable role of change agent, to maintain change once it has been started. ${ }^{[15]}$ These phases related to the components of the nursing process that includes assessment to identify the problem, planning for a suitable intervention, implementation of the essential change and evaluation of its effect. These phases encourage the effective implementation of strategies for empowering the life quality and antipsychotic adherence of patients with schizophrenia that contributes to creat the desirable change.

\subsubsection{Assessment phase}

The researchers reviewed all psychiatric outpatients' records in order to select those who meet this study inclusion criterion. The recruited clients were requested to share in this study after establishing the trusting relationship and explaining the aim of the study. The process continued till desired subject number (60 patients) was reached. The recruited patients underdone a pre-test using soci-demographic data, the quality of life scale, and the medication adherence rating scale. This was applied to interviewing patients on an individual basis by the researchers. Each interview lasted for 35-50 minutes, according to the patient's attention, concentration, willingness to cooperate or talk. Patient's clinical data were double checked from their clinical charts.

\subsubsection{Program development phase}

The program was developed by the researchers depended on data from assessment phase and the literature review. The program content was produced. The content stressed mainly on the different information and effective strategies for nurses empowering the life quality and antipsychotic adherence of patients with schizophrenia disorder. It included information on symptoms, causes, and treatment of schizophrenia; medication and its' side effects; signs and symptoms of relapse; stress management; relaxation techniques and increase self-awareness. Program objectives were established. The suitable educational strategies selected according to session content.

\subsubsection{Implementation phase}

Before implementation of the program, permission was obtained through official letters to secure approval about the

Published by Sciedu Press agenda of the program, place and time performing was arranged with the hospital administrator and staff in order not to interfere with their work.

The researchers divided the implementation phase of the program into two parts:

Part I: It includes 3 educational sessions. Each session of the interview taken for 35-50 minutes, relying on the patient's ability. During each session, the participants are given breaks for 10 minutes. It included information on symptoms, causes, and treatment of schizophrenia; medication and its' side effects; signs and symptoms of relapse;

Part II: It includes 5 training sessions for the applied training part, through demonstration and re-demonstration by the patients under observation of researchers. It included stress management; relaxation techniques and increase selfawareness were applied.

\subsubsection{Evaluation phase}

The evaluation of the implemented program was done by:

- Reapply of stress management and relaxation technique.

- Immediately after the implementation of the program (post-test 1).

- Three months later, after the program implementation (follow-up test 2).

\subsection{Statistical design}

Statistical Package for Social Sciences (SPSS), version 21 was utilized. Descriptive data as a percentage, frequency, the mean and standard deviation "Mean \pm SD" were employed. In addition to data analysis as Pearson's correlation and McNemar's test. The degrees of the significance of the results were considered as follows: $p$-value $>.05$, Not Significant (NS); $p$-value $\leq .05$, Significant (S), $p$-value $\leq .001$, Highly Significant (HS).

\section{RESULT}

As shown in Table 1, the patients' age ranged from 23-55 years with a mean age of $34.0 \pm 9.38,80 \%$ are males, $60 \%$ reside in rural areas, $41.7 \%$ have secondary education, and $50 \%$ are single. As regards occupation, $75 \%$ of them aren't working, and for $80 \%$ income was insufficient. Considering $66.7 \%$ have a negative family history of schizophrenia, $75 \%$ have a history of admission, and $75 \%$ of them the duration of the disease ranged from 5 to 10 years. 
Table 1. The socio-demographic characteristics of the studied subjects $(\mathrm{n}=60)$

\begin{tabular}{|c|c|c|}
\hline Socio-demographic & No & $\%$ \\
\hline \multicolumn{3}{|l|}{ Age/years } \\
\hline $20-<30$ & 18 & 30 \\
\hline $30-<40$ & 21 & 35 \\
\hline $40-<50$ & 12 & 20 \\
\hline $50+$ & 9 & 15 \\
\hline Range & $23-55$ & \\
\hline Mean \pm SD & $34.0 \pm 9.38$ & \\
\hline \multicolumn{3}{|l|}{ Gender } \\
\hline Male & 48 & 80 \\
\hline Female & 12 & 20 \\
\hline \multicolumn{3}{|l|}{ Residence } \\
\hline Urban & 24 & 40 \\
\hline Rural & 36 & 60 \\
\hline \multicolumn{3}{|l|}{ Degree of education } \\
\hline Illiterate & 10 & 16.7 \\
\hline Primary education & 20 & 33.3 \\
\hline Secondary education & 25 & 41.7 \\
\hline University & 5 & 8.3 \\
\hline \multicolumn{3}{|l|}{ Married conditions } \\
\hline Single & 30 & 50 \\
\hline Married & 19 & 31.7 \\
\hline Widowed & 3 & 5 \\
\hline Divorced & 8 & 13.3 \\
\hline \multicolumn{3}{|l|}{ Occupation } \\
\hline Working & 15 & 25 \\
\hline Not working & 45 & 75 \\
\hline \multicolumn{3}{|l|}{ Income/month } \\
\hline Sufficient & 12 & 20 \\
\hline Insufficient & 48 & 80 \\
\hline \multicolumn{3}{|c|}{ Family history of schizophrenia } \\
\hline Positive & 20 & 33.3 \\
\hline Negative & 40 & 66.7 \\
\hline \multicolumn{3}{|l|}{ Previous admission } \\
\hline Yes & 45 & 75 \\
\hline No & 15 & 25 \\
\hline \multicolumn{3}{|l|}{ Duration of disease } \\
\hline Less than 5 years & 9 & 15 \\
\hline $5-10$ & 45 & 75 \\
\hline More than 10 & 6 & 10 \\
\hline
\end{tabular}

Table 2 reveals that $55 \%$ of the studied patients have a nega- tive attitude toward compliance of drug before the training program, while $95 \%$ of them have a positive attitude of medication obedience immediately after the intervention, and all of them $(100 \%)$ at after three months with a highly statistically significant difference $(p<.001)$.

Figure 1 symbolizes that in all fields of the life quality in the immediate and after three months of the program are higher than before the program, especially in social and personal relations, and general level of activity.

Table 3 reveals that there is a positive relationship found between the life quality and antipsychotic compliance, but no statistically significant relationship before, immediately after and after three months of the instruction.

\section{Discussion}

A high proportion of patients, either psychiatric or not psychiatric, do not fully comply with long-term treatments leading to frequent drop-out episodes. ${ }^{[16]}$ The term adherence refers to an active participation in the treatment plan by the patient and not a passive of therapeutic strategies. ${ }^{[17]}$ Psychotropic drugs decrease the positive symptoms of schizophrenia and inhibit deterioration. Nearly, three-quarters of clients relapse through one year as if psychotropic drugs are stopped. ${ }^{[18]}$ The noncompliance with medication occurs the following discharge, for that reason, follow-up is essential for inhibiting noncompliance with antipsychotic drug and early identification of signs and symptoms of deterioration. ${ }^{[19]}$ Interventions aim to directly improve the insight or the realization of the negative outcome of poor insight (non-adherence, social isolation, indifference for people who are dealing with them and health system) should be developed. ${ }^{[20]}$ Consequently, the management approach should be involved patients can progress their compliance with the antipsychotic drug, relieve symptoms and improvement of the life quality and nursing guidelines that include training the patients about self-care, action planning, social interaction skills, and relaxation strategies. Therefore the current research aim was to assess the effective strategies for nurses empowering the life quality and antipsychotic adherence of patients with schizophrenia.

Table 2. The distribution of the studied subjects according to medication adherence before, immediately after and after three months of the program

\begin{tabular}{|c|c|c|c|c|c|c|c|}
\hline \multirow{2}{*}{ Studied variables } & \multicolumn{2}{|c|}{ Before } & \multicolumn{2}{|c|}{ Immediately after } & \multicolumn{2}{|c|}{ After three months } & \multirow{2}{*}{$\begin{array}{l}\text { Test McNemar } \\
p \text {-value }\end{array}$} \\
\hline & No & $\%$ & No & $\%$ & No & $\%$ & \\
\hline \multicolumn{8}{|c|}{ Adherence to medication } \\
\hline Positive attitude & 27 & 45 & 57 & 95 & 60 & 100 & $.001^{*}$ \\
\hline Negative attitude & 33 & 55 & 3 & 5 & 0 & 0.0 & \\
\hline
\end{tabular}




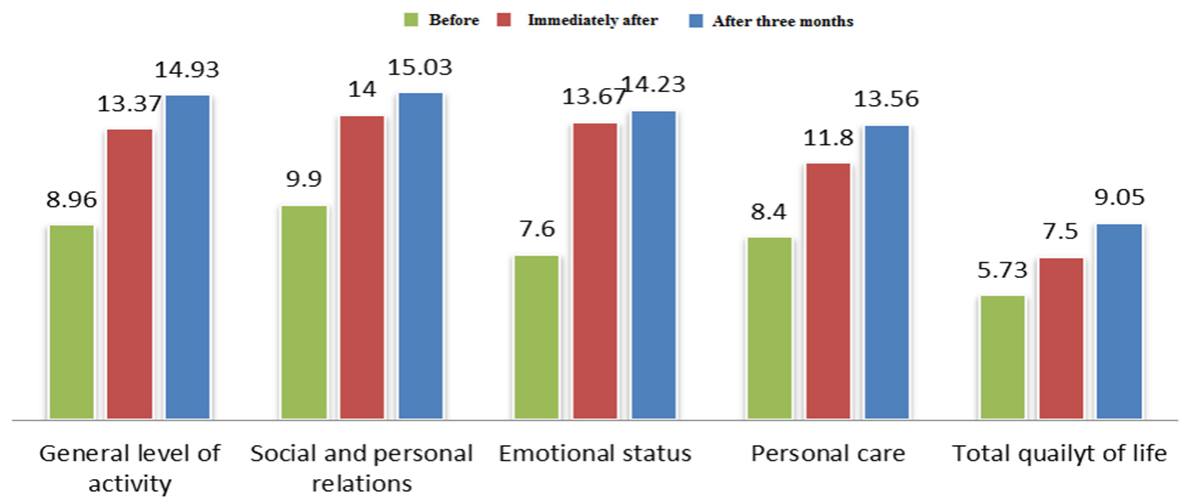

Figure 1. The life quality among the studied patients before, immediately after and after three months of the program

Table 3. The relation between the life quality and medication adherence among the studied patients before, immediately after and after three months of the program

\begin{tabular}{|c|c|c|c|c|c|c|}
\hline \multirow{3}{*}{ Studied variables } & \multicolumn{6}{|c|}{ The Life Quality } \\
\hline & \multicolumn{2}{|c|}{ Before } & \multicolumn{2}{|c|}{ Immediately after } & \multicolumn{2}{|c|}{ After three months } \\
\hline & $r$ & $p$-value & $r$ & $p$-value & $r$ & $p$-value \\
\hline Medication adherence & 0.117 & .538 & 0.299 & .109 & 0.313 & .093 \\
\hline
\end{tabular}

The present study results revealed that patients' age ranged from twenty-three to fifty-five years. In this respect, a study done by Haddad et al. ${ }^{[21]}$ revealed that the median age of thirty-eight years was found in their study. Schizophrenia can decrease life expectancy among patients by twenty-five to thirty years. ${ }^{[22]}$

The current study indicated that half of the studied sample was single, this is due to that a patient has disturbances in many areas of his/her relationship and interaction with others. This result came in line with that of a study on the quality of life of patients with schizophrenia carried out by Cardoso et al. ${ }^{[23]}$ who pointed out that patients with this disorder, especially men, face difficulties to keep up marital relations, which significantly affects their quality of life. During the interviews, the interviewers reported difficulties to establish and maintain stable marital relationships, this may be due to that stable marital relationships need more responsibility and effort from the person to keep this relationship, which is not found among patients with schizophrenia.

In the present study, results showed that three-quarters of the clients are not working. This finding may be due to those patients having many symptoms related to their illness, adding to the side effects of drugs can lead to non-compliance with the job responsibility. This result was consistent with that of a study conducted by Cardoso et al. ${ }^{[24]}$ which revealed that the people with severe mental disorders are generally unemployed.
The previous result goes online with, those of several studies as those of Schennach et al. ${ }^{[25]}$ which demonstrated that non-adherence in clients with schizophrenia present with the greater occurrence of relapse and the negative influence of working and social life. Furthermore, schizophrenia is associated with high incidence of difficulty maintaining employment, and dysfunctional social relationships, all of which make living a normal, productive life extremely challenging for a schizophrenic patient. ${ }^{[26]}$

The present study findings stated more than half of the studied subjects had a negative attitude toward compliance with medication before the training program. The researchers observed it might be expected as the medical staff doesn't give the patients and their caregivers the complete information regarding their medications, including action, therapeutic effect, and side effects of the drug. Hence, the caregivers give patients their drugs in an irregular manner and do not give the antipsychotic drugs as the physician ordered. These findings were similar to those of the study done by Rosa and Elkis ${ }^{[27]}$ who analyzed, potentially influencing factors to drug treatment compliance related behavior showed that more than half of patients did not comply with the drugs.

The results of the current study displayed an extremely statistically significant difference between before, immediately after and after three months of the program regarding drug compliance as less than half in the pre-test showed positive attitudes toward medication adherence; while in the imme- 
diately after the instructions, they represented a great majority, and all the studied patients had the positive attitude to comply with medication after three months of the program implementation. These results were supported by those of Chadzynska and Chadzynska ${ }^{[28]}$ clarified that therapeutic approaches increase a person's cope ability and promote his/her functioning, they provide information about a course of illness, working on cognitive and emotional statuses.

The result of current study represented that all domains of the life quality in the immediately after and after three months of the program are higher than before the intervention, especially in social and personal relations, and general level of activity. This means that the life quality was enhanced after the training program and during follow up. The results of the present study are congruent with those of a study done by Degmecié et al. ${ }^{[2]}$ who explained that the educational program has been developed to increase the knowledge, understanding, and insight of people about their disorder and maximize the effectiveness of their treatment. It is delineated as a strategy for instruction patients about mental disorders, their treatments, personal coping skills, and improves their quality of life.

The result of the present study discovered that there is a positive relationship found between the life quality and medication compliance in before, immediately after and after three months of the strategies' implementations. This is meant that when medication adherence increased the quality of life is improved. However, the results displayed no statistically significant relationship between the life quality and medication compliance, may be attributed to the small sample size in the present study. This result is similar to a study carried out by $\mathrm{Niolu}^{[30]}$ identified an important role that has been assigned recently to the notion of subjective well-being and life quality, even in patients submitted to antipsychotic drugs.

Whereas some studies have attempted to measure the relationship between the life quality with medication adherence in clients with schizophrenia and even the results of such studies provide overturning results as those of a recent study conducted by Ogunnubi et al. ${ }^{[31]}$ who reported that participants with poorer drug adherence were more likely to have poorer mean scores on an overall the life quality, physical health, satisfaction and psychological WHO QoL scale. In this respect, Dilla, Ciudad and Álvarez ${ }^{[32]}$ who explained non-adherence can aggravate patients' occupational and social functioning, resulting in decreased the quality of life and increased use of health care resources of the society. Nonadherence can have significant economic consequences since it is strongly associated with relapse of schizophrenia.
The findings of the current study were supported by Sauvanaud et al. ${ }^{[33]}$ who reported that educational instruction has a positive effect on decreasing frequencies in schizophrenia. The instruction revealed a significant advantage of objective life quality and psychological happiness for the patient.

Our program might be enhanced the patients' compliance with drugs because the patients with schizophrenia need more information about the medication which leads to decrease symptoms, signs and side effects of the drugs. The progress of a patient understanding of the antipsychotic medications which improve their general level of daily activity, self-care, social and personal relations, and emotional status, then improving their quality of life. The results of the present study are consistent with Soliman, Mahdy and Fouad ${ }^{[34]}$ who explained that the psycho-education has a significant role in the deficiency of severity of symptoms to increase attention regarding overall stages of the disorder and early management.

This result was reversed with Mitchell and Selmes ${ }^{[35]}$ who found the patients with poor drug compliance had worse scores on all dominions of the life quality associated with medication compliance clients, non-adherence to medications may lead to the relapse or worst of the symptoms and the deterioration of patients' psychiatric health and accordingly affect their life quality.

\section{Limitations}

- Limitations of the study concerned the challenges involved in difficulty to sustain patient's concentration or attention during interviewing him/her.

- The emotional condition of some patients was a hindrance to contact or communicate with them.

- A number of patients were illiterate, so long time was taken to complete the sheets that were done by the researchers.

\section{Conclusion}

Building on the results of the present study concluded and a hypothesis that nursing strategies were effective in the empowerment of the life quality and antipsychotic drug compliance for patients with schizophrenia.

\section{Recommendations}

- The psychiatric nurse must note the effectiveness and side effects of antipsychotics in the patients with schizophrenia as soon as possible, to improve their health state, medication compliance, and life quality.

- The psychiatric nurse must use the effective strategies for empowering the life quality and antipsychotic adherence of patients with schizophrenia. 
- Mental health teams need to develop more innovative programs for patients with schizophrenia and it can be more effective to involve the families as an active team of the healthcare members by assigning specific tasks for the family caregivers and allocating the necessary resources to accomplish such tasks.

\section{ACKNOWLEDGEMENTS}

The authors gratefully extend their appreciation to the direc- tor of the hospital, matron and doctors and all nurses in the outpatient clinic, they wish to express their deepest gratefulness to all patients and their families who helped us in fulfilling our responsibilities toward this research.

\section{CONFlicts of InTEREST Disclosure}

The researchers proclaim that there is no conflict about this article.

\section{REFERENCES}

[1] Nordqvist C. Understanding the symptoms of schizophrenia. Medical News Today. 2017. Available from: https://www.medicalnewst oday.com

[2] Adewuya A, Makanuola R. Subjective quality of life of Nigerian schizophrenia patients: socio-demographic and clinical correlates. Acta Psychiatr Scand. 2009; 120: 160-164. PMid:19416124 https://doi.org/10.1111/j.1600-0447.2009.01395.x

[3] Ascher-Svanum H, Faries D, Zhu B, et al. Medication adherence and long-term functional outcomes in the treatment of schizophrenia in usual care. J Clin Psychiatry. 2006; 67: 453-460. PMid:16649833 https://doi.org/10.4088/JCP.v67n0317

[4] Zipursky R. Why are the outcomes in patients with schizophrenia so poor? J Clin Psychiatry. 2014; 75(2): 20-24. PMid:24919167 https://doi.org/10.4088/JCP.13065su1.05

[5] World Health Organization. Adherence to long-term therapies: Evidence for action. Geneva: World Health Organization; 2003.

[6] Mueser K, McGurk S. Schizophrenia. Lancet. 2004; 363(9426): 2063-2072. PMid:15207959

[7] Emsley R, Chiliza B, Asmal L, et al. The nature of relapse in schizophrenia. BMC Psychiatry. 2013; 13: 50. PMid:23394123 https://doi .org/10.1186/1471-244X-13-50

[8] Klingberg S, Schneider S, Wittorf A, et al. Collaboration in outpatient antipsychotic drug treatment: Analysis of potentially influencing factors. Psychiatry Res. 2008; 161(2): 225-234. PMid:18922582 https://doi.org/10.1016/j.psychres . 2007.07.027

[9] Maneesakorn S, Robson D, Gournay K. An RCT of adherence therapy for people with schizophrenia in Chiang Mai. Thailand. J Clin Nurs. 2007; 16: 1302-1312. PMid:17584349 https://doi.org/ $10.1111 / j .1365-2702.2007 .01786 . x$

[10] Shuler K. Approaches to improve adherence to pharmacotherapy in patients with schizophrenia. Patient Preference and Adherence. 2014; 8: 701-714. PMid:24868149 https://doi.org/10.2147/ PPA.S59371

[11] Dassa D, Boyer L, Benoit M, et al. Factors associated with medication non-adherence in patients suffering from schizophrenia: A cross-sectional study in a universal coverage healthcare system. Aust N J Z Psychiatry. 2010; 44(1): 921-928. PMid:20932206 https://doi.org/10.3109/00048674.2010.493503

[12] Medical Dictionary for the Health Professions and Nursing. Insight. 2012. Available from: https://www.medical-dictionary.th efreedictionary.com/insight

[13] Lehman A. A quality of life interview for the chronically mentally ill. Evaluation and Program Planning. 1988; 11: 51-62. https: //doi.org/10.1016/0149-7189(88)90033-X

Published by Sciedu Press
[14] Thompson K, Kulkarni A, Sergejew A. Reliability and validity of a new Medication Adherence Rating Scale (MARS) for the psychoses. Schizophrenia Research. 2000; 42(3): 241-247. https: //doi.org/10.1016/S0920-9964(99)00130-9

[15] Lippitt R, Watson J, Westley B. The Dynamics of Planned Change (New York, Harcourt Brace, 1958). In: Kozier B, Erb G, Berman A and Burke K. Fundamentals of Nursing: Concepts, Process, and Practice. 6th ed. Prentice Hall Health. New Jersey. 2000.

[16] Sendt K, Tracy D, Bhattacharyya S. A systematic review of factors influencing adherence to antipsychotic medication in schizophrenia-spectrum disorders. Psychiatry Res. 2015; 225: 14-30 PMid:25466227 https://doi.org/10.1016/j.psychres. 201 4.11 .002

[17] Pasadas C, Manso F. Psycho-education: A strategy for preventing relapse in patients with schizophrenia. International Journal of Nursing. 2015; 2(1): 89-102.

[18] Frankenburg F, Albucher R, Talavera F. Schizophrenia Treatment \& Management. Medscape. 2018. Available from: https://www.me dscupe.com

[19] Aldridge M. Addressing non-adherence to antipsychotic medication: A harm-reduction approach. Journal of Psychiatric and Mental Health Nursing. 2011; 1: 12.

[20] Cardoso A. O Insight em Psiquiatria. Revista de Psicologia. 2008; 20(2): 347-356.

[21] Haddad P, Brain C, Scott J. Nonadherence with antipsychotic medication in schizophrenia: Challenges and management strategies. Patient Related Outcome Measures. 2014; 5: 43-62. https ://doi.org/ 10.2147/PROM. S42735

[22] Colton C, Manderscheid R. Congruencies in increased mortality rates, years of potential life lost, and causes of death among public mental health clients in eight states. Prev Chronic Dis. 2006; 3: 1-14.

[23] Cardoso C, Caiaffa W, Bandeira M, et al. Quality of life and professional dimension in schizophrenia: Comparison by sex. Cad Public Health. 2006; 22(6): 1303-1314.

[24] Cardoso L, Galera S. Mental patients and their compliance profile to psycho-pharmacological treatment. Rev Esc Enferm USP [Internet] 2010; 43(1): 161-167. Available from: http://www.scielo.br/ pdf/reeusp/v43n1/en_21.pdf

[25] Schennach R, Obermeier M, Meyer S, et al. Predictors of relapse in the year after hospital discharge among patients with schizophrenia. Psychiatr Serv. 2012; 63: 87-90. PMid:22227766 https://doi.org/10.1176/appi.ps. 201100084

[26] Stern T. Massachusetts General Hospital Comprehensive Clinical Psychiatry. 1st ed. Philadelphia, PA: Mosby Elsevier; 2008.

[27] Rosa M, Elkis H. Adherence in schizophrenia. Rev Psiquiatr Clin 2007; 34 (2): 189-192. 
[28] Chadzynska M, Chadzynska K. The participation of patients with schizophrenia in psychoeducation. The analyses from the patient's perspective. Archives of Psychiatry and Psychotherapy. 2011; 2: 6772.

[29] Degmecié D, Pozgain I, Filakovié P. Psychoeducation and compliance in the treatment of patients with schizophrenia. Coll. Antropol. 2007; 31(4): 1111-1115. PMid: 18217468

[30] Niolu C, Bianciardi E, Di Lorenzo G, et al. Enhancing adherence, subjective wellbeing and quality of life in patients with schizophrenia: Which role for long-acting risperidone? Ther Adv Psychopharmacol. 2015; 5(5): 278-288. Available from: http://ww w. sagepub.co.uk/journalsPermissions.nav https://doi. org/10.1177/2045125315596897

[31] Ogunnubi O, Olagunju A, Aina O, et al. Medication adherence among Nigerians with schizophrenia: Correlation between clinicodemographic factors and quality of life. PMCID. 2017; 9(1): 6889.
[32] Dilla T, Ciudad A, Álvarez M. Systematic review of the economic aspects of non-adherence to antipsychotic medication in patients with schizophrenia. Patient Preference and Adherence. 2013; 7: 275-284. PMid:23589681

[33] Sauvanaud F, Kebir O, Vlasie M, et al. Therapeutic benefit of a registered psychoeducation program on treatment adherence, objective and subjective quality of life: French pilot study for schizophrenia. Encephale. 2017; 43: 235-240. PMid:27658989

[34] Soliman E, Mahdy R, Fouad H. Impact of psychoeducation program on quality of life of schizophrenic patients and their caregivers. Egyptian Journal of Psychiatry. 2018; 39: 35-41. Available from: http://www.new.ejpsy.eg.net

[35] Mitchell J, Selmes T. Why don't patients attend their appointments? Maintaining engagement with psychiatric services. Adv Psychiatr. Treat. 2007; 13: 423-434. https://doi.org/10.1192/apt.bp .106 .003202 